\section{GO-AHEAD FOR CONTINUOUS REGISTRATION}

Continuous (lifelong) registration of dental patients is to be introduced in Scotland from 1 April 2010 following new arrangements imposed by the Scottish Government Health Directorates (SGHD).

The Scottish Government's policy approach is that there should be no automatic ending of registration after a given period of time and it believes that continuous registration will help develop a more stable relationship between a dentist and a patient. SGHD cites that this fits with the need to plan care on a long term basis and to monitor oral health over time.

However, the British Dental Association (BDA) has expressed disappointment at the news. Dr Robert Kinloch, newly elected Chair of the BDA's Scottish Dental Practice Committee, said, 'Continuous registration sends all the wrong signals about the value of patients visiting their dentist regularly.
It encourages neglect of personal oral health, undermines modern, preventive approaches to care and devalues the relationship between clinician and patient. It also removes the responsibility of patients to comply with recall intervals advised by their dentist. Scotland already faces unenviable rates of oral cancers. The fear among dentists is that more cases will now go undetected.'

He called for co-operation with the profession on arrangements to introduce continuous registration, and urged the Government to work hard to promote regular attendance to patients and ensure that the efforts of the profession in encouraging patients to visit them regularly are not undone.

Dr Kinloch added, 'In the short-term, dentists must be provided with the information they need about individuals who have not been seen in practice for the last three years to allow them to make

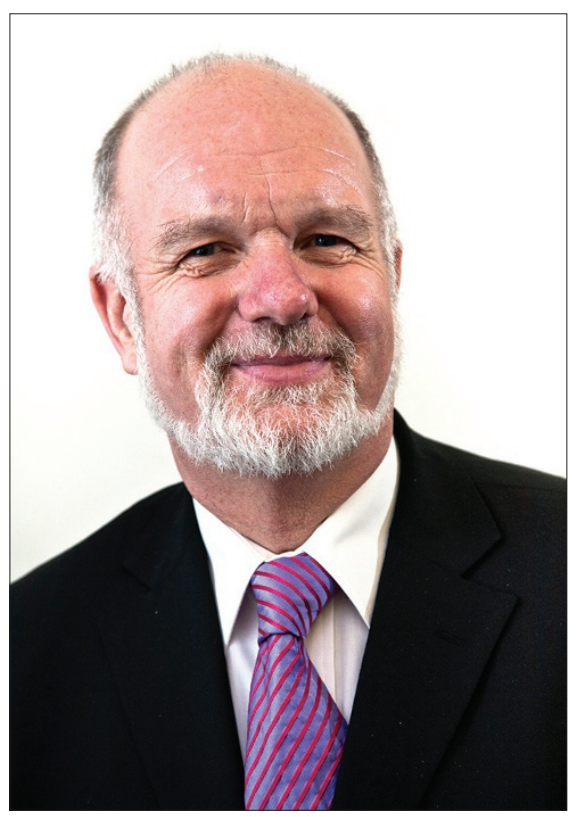

Chair of the BDA's Scottish Dental Practice Committee Dr Robert Kinloch

a decision about whether the continued registration of those patients will affect the ability of the practice to care for its regularly-attending patients.'

\title{
NEW BLACKPOOL DENTAL EDUCATION CENTRE OFFICIALLY OPENS
}

Blackpool's new Dental Education Centre (DEC) was officially opened recently by the Chief Dental Officer for England, Dr Barry Cockcroft. The DEC - one of four throughout Lancashire - will provide training for students from the University of Central Lancashire's (UCLan) School of Dentistry, with the hope that once qualified they will continue to work in Blackpool.

It features a wide range of stateof-the-art treatment and teaching facilities including high specification video-conferencing, allowing lectures to be delivered to students at the DEC by tutors in Preston, a hi-tech decontamination suite, emergency treatment room and phantom heads for the students to work on. There is also equipment for those with disabilities and special needs, which enables patients to receive treatment without the necessity of leaving their wheelchairs.

Professor Lawrence Mair, Head of the School of Dentistry at UCLan, said, 'We are extremely excited about this entirely new model of teaching

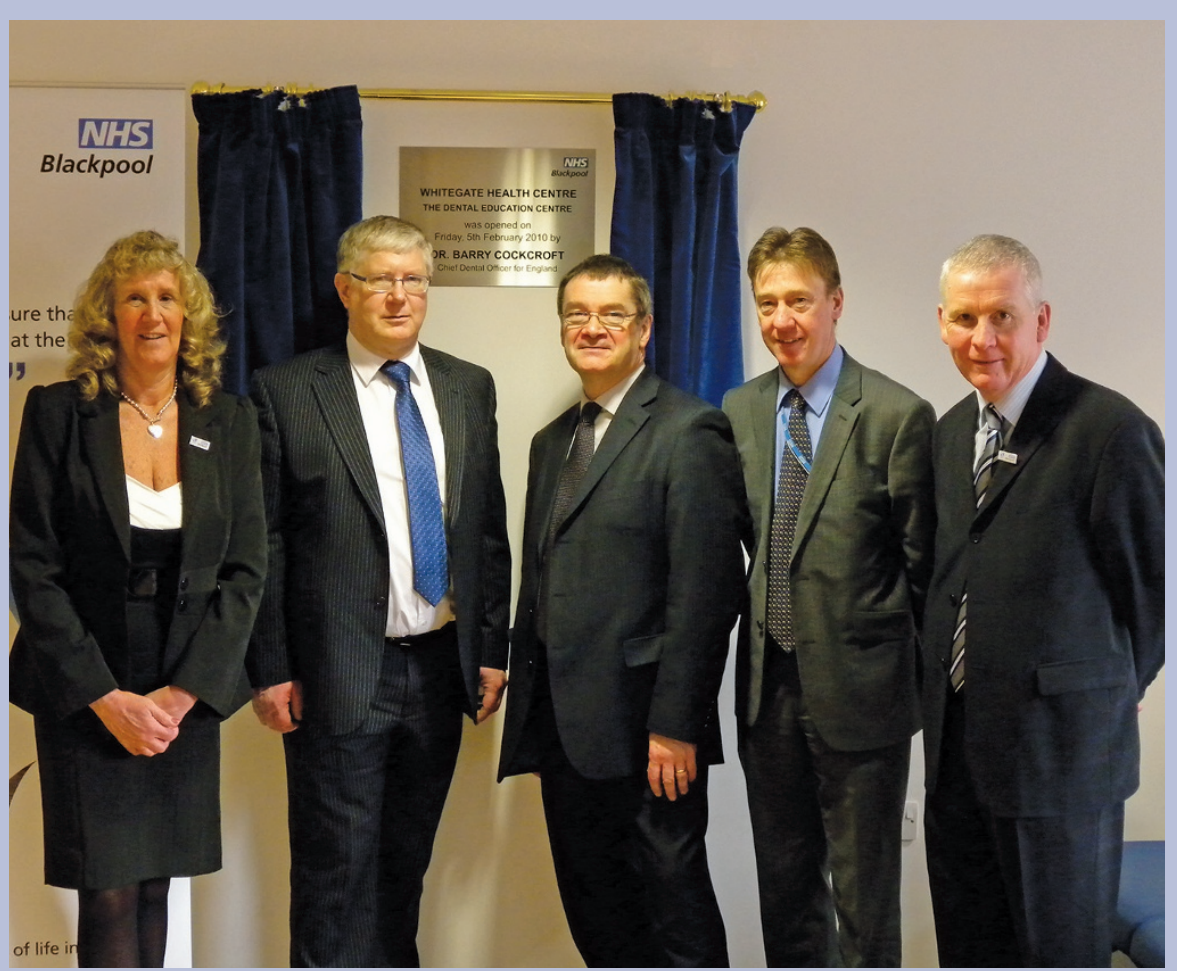

dentistry, which puts clinics in local communities, rather than city centres, and has led us to revise our traditional teaching techniques. The new model of dental education is working very well: our third year students already interact with their patients in a very professional way.' 